\title{
Estudio comparativo de detección del virus papiloma humano (VPH) en muestras citológicas y biopsias de cuello uterino
}

\author{
Angélica Melo $A^{1 a}$, Iván Roa $E^{1}$, Sonia Montenegro $H^{2}$, \\ Italo Capurro $\mathrm{V}^{3}$, Juan Carlos Roa $\mathbf{S}^{1}$. \\ Detection of human papilloma virus \\ in cytologic samples or biopsies of \\ the cervix
}

Background: The DNA quality for the detection and typification of Human Papilloma Virus (HPV) varies according to the type of sample in which it is studied. This may affect the sensitivity and specificity of the method employed. Aim: To study the yield and specificity of HPV detection and typification in uterine cervical samples obtained by cervical brushing fresh frozen and formalin fixed tissue. Material and methods: Cytological, fresh frozen and fixed tissue samples from 44 patients (nine with low grade lesions and 35 with high grade lesions) were studied. Nested polymerase chain reaction for genes E6/E7 was used to typify HPV groups as low risk or high risk. Results: Of all the cytological samples obtained by brushing $84 \%$ of fixed samples and $43 \%$ of fresh frozen samples were positive for HPV. The yields were significantly different when comparing brushing with fixed tissue or fresh frozen tissue and fixed tissue with fresh frozen tissue $(\mathrm{p}<0.05)$. The frequency of high risk HPV fluctuated from $41 \%$ in fresh frozen tissue to $98 \%$ in cytological samples. Low risk HPV was detected in $16 \%$ of fresh frozen tissue and $68 \%$ of cytological samples. A mixed infection was detected in $66 \%, 41 \%$ and $14 \%$ of cytological, fresh frozen and fixed tissue samples respectively. Conclusions: Cytological samples obtained by brushing had the highest yield for the detection of cervical infection with HPV (Rev Méd Chile 2005; 133: 639-44).

(Key Words: Cytological techniques; Cytopathology; Papillomavirus, human)

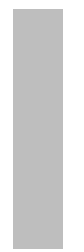

\footnotetext{
Recibido el 13 de agosto, 2004. Aceptado en versión corregida el 15 de abril, 2005. Financiado por la Universidad de La Frontera a través del Proyecto DIUFRO № 2116. ${ }_{1}^{1}$ Departamento de Anatomía Patológica, Facultad de Medicina, Universidad de la Frontera, Temuco, Chile. ${ }^{2}$ Molecular Immunogenetics Laboratory, Ochsner Clinic Foundation, New Orleans, LA, USA. ${ }^{3}$ Departamento de Obstetricia y Ginecología, Facultad de Medicina, Universidad de La Frontera, Temuco, Chile. aTecnólogo Médico.
}

Correspondencia a: Dr. Juan Carlos Roa. Departamento de Patología, Facultad de Medicina, Universidad de la Frontera. Manuel Montt 112. Código Postal 478-1176. Temuco, Chile. E-mail: jcroa@ufro.cl 
T a infección por el virus papiloma humano ـ(VPH) es el principal factor etiológico de lesiones intraepiteliales y cáncer cervicouterino (CCU) ${ }^{1,2}$. Según la frecuencia de su asociación con cáncer y lesiones preneoplásicas, los distintos genotipos virales de VPH son clasificados en bajo y alto riesgo (BR y $\mathrm{AR}$ ) oncogénico. Los tipos virales de AR se encuentran en 90\% de los carcinomas y lesiones preneoplásicas de alto grado. Los tipos de VPH de BR generalmente están asociados con lesiones benignas o con muy bajo potencial de malignidad ${ }^{2,3}$.

La detección de signos morfológicos por infección de VPH, es sencilla mediante el examen citológico (PAP) o histopatológico. Sin embargo, el PAP presenta un significativo porcentaje de falsos negativos que alcanza, dependiendo del laboratorio, hasta $20-30 \%$ de los frotis examinados ${ }^{4,5}$. Además, debe considerarse que la detección indirecta de VPH mediante estos exámenes, no permite la tipificación viral, importante información en el momento de categorizar subgrupos de pacientes desde una perspectiva clínica práctica. En ese sentido, diferentes grupos han utilizado la técnica de reacción de la polimerasa en cadena (PCR) para su detección y tipificación ${ }^{6-8}$. Se han descrito diferentes protocolos con iniciadores de consenso dirigidos a los genes L1 y E6/E7, que permiten, por un lado, la detección de VPH y por otro, la tipificación de un gran número de genotipos virales prevalentes en el tracto anogenital ${ }^{9-12}$.

El tipo de muestra a utilizar en la tipificación de VPH es fundamental, debido a que la calidad del ADN extraído puede variar considerablemente, afectando la sensibilidad y especificidad del método usado ${ }^{13,14}$. El tamaño de los fragmentos de ADN obtenidos de la muestra, tiene un efecto inverso sobre la eficacia de la PCR. Se ha realizado detección de VPH a partir de diferentes tipos de muestras, como tejido de archivo ${ }^{11,15}$, tejido congelado ${ }^{13}$, cepillo endocervical (cepillado $)^{16,17}$, espátula de Ayre ${ }^{16}$ e, incluso, desde frotis teñidos ${ }^{18}$. Sin duda, cada método tiene sus ventajas o desventajas. De esta manera, para elegir el mejor material y método, se requiere de la evaluación de parámetros como dificultad en la toma de la muestra, sensibilidad y especificidad, costo y reproducibilidad del método de detección.
Para la amplificación de ADN proveniente de material de archivo, se recomienda usar iniciadores que amplifiquen secuencias de ADN viral no superior a $200 \mathrm{pb}^{19-21}$. Nuestros resultados, con un método combinado de PCR y enzimas de restricción (RFLP) para la tipificación de VPH en material fijado en formalina e incluido en parafina, han sido previamente comunicados ${ }^{22}$. En el presente estudio, nuestro objetivo fue evaluar el rendimiento para la detección de VPH y su tipificación, en muestras obtenidas por cepillado, tejido fresco de conos por asa LEEP y material de archivo de biopsias de cuello uterino.

\section{MATERIAL Y MÉTODO}

Pacientes. Se incorporaron al estudio 44 pacientes del Policlínico de Patología Cervical del Hospital Hernán Henríquez Aravena de Temuco, entre junio y agosto de 2002. Todas con antecedentes de lesiones cervicales en citologías o biopsias previas.

Muestras. A cada paciente se le tomó 3 muestras: una obtenida mediante cepillado (CB), una muestra en fresco del cono por asa LEEP y una muestra fijada en formalina tamponada al 10\%, e incluida en parafina del histológico de rutina.

La primera muestra fue obtenida una vez realizado el PAP, se colocó el cepillo en un tubo de $15 \mathrm{ml}$ que contenía $3 \mathrm{ml}$ de buffer TE $\mathrm{pH} 7.4$ (10 mM Tris.Cl, $1 \mathrm{mM}$ EDTA pH 8). Este material fue procesado de inmediato 0 mantenido a $4^{\circ} \mathrm{C}$ por un máximo de $24 \mathrm{~h}$, hasta realizar la extracción del ADN.

La segunda muestra se obtuvo del material en fresco de la biopsia por asa LEEP. Un fragmento de tejido de aproximadamente $0,5 \times 0,5 \times 0,2 \mathrm{~mm}$, se colocó en un tubo con gel criopreservante (Jung, Alemania) y se congeló a $-20^{\circ} \mathrm{C}$ hasta su procesamiento.

La tercera muestra se obtuvo del material de archivo. Se seleccionaron áreas con lesión que se procesaron en forma similar al tejido fresco.

Extracción de ADN. Se realizó mediante el kit Puregen $\mathrm{C}^{\mathrm{TM}}$ DNA Isolation System (Gentra, USA), siguiendo las instrucciones del fabricante. La integridad del ADN fue verificada mediante electroforesis en gel de agarosa al $2 \%$. 
Procesamiento de las muestras:

Muestra cepillado (CB). Se agitó en vortex por 30 $\mathrm{s}$ y posteriormente se centrifugó $1,5 \mathrm{ml}$ de la muestra a $17.160 \mathrm{~g}$ por $15 \mathrm{~min}$ a $4^{\circ} \mathrm{C}$. El concentrado celular se resuspendió en buffer de lisis Puregene, con proteinasa $\mathrm{K}$ a una concentración de $160 \mathrm{ug} / \mathrm{ml}$.

Muestra de tejido fresco congelado (TC). Se fragmentó con bisturí mediante procedimiento estéril sobre un portaobjeto ${ }^{23}$. Los fragmentos no mayores a $2 \mathrm{~mm}$ de diámetro, fueron digeridos en buffer de lisis Puregene, con proteinasa $\mathrm{K}$ a una concentración de $1 \mathrm{mg} / \mathrm{ml}$.

Tejido fijado (TF). Con material estéril y desechable, se obtuvo 5 cortes de 10 micras y se realizó disección manual de la lesión identificada microscópicamente. El tejido obtenido se colocó en un tubo de $1,5 \mathrm{ml}$ que contenía buffer de lisis Puregene, con proteinasa $\mathrm{K}$ a una concentración de $1 \mathrm{mg} / \mathrm{ml}$. Las muestras se incubaron a $55^{\circ} \mathrm{C}$ por $3 \mathrm{~h}$ o hasta digestión total del material.

La calidad del ADN de todas las muestras fue verificada mediante amplificación por PCR para el gen ß-globina que amplifica un producto de $268 \mathrm{pb}^{23}$.

Detección y tipificación de VPH por PCR. Se utilizó una PCR de consenso en nido para los genes E6/
E7, usando para la primera amplificación los iniciadores LCRs/E7as que producen un segmento de 650 pares de bases (pb). Para la segunda amplificación, que genera fragmentos entre 230$270 \mathrm{pb}$, se usaron los iniciadores PU1M-PU2R, que permitieron subtipificar los tipos virales en AR (HPV 16, 18, 31, 33, 35, 52) y PU2R-PU-31B en los de BR (HPV 6, 11) $)^{9,15}$.

En cada PCR se incluyeron 2 controles positivos de VPH de AR y BR (plásmidos VPH16 y VPH11), un control blanco y un control negativo (ADN normal). Los productos PCR se visualizaron mediante electroforesis en geles de agarosa al $2 \%$ teñido con bromuro de etidio.

Condiciones de las PCR en nido ("nested"). 30 ciclos (primera amplificación) y 40 ciclos (segunda amplificación), con temperaturas de hibridación de $40^{\circ}$ a $55^{\circ} \mathrm{C}^{22}$.

Interpretación de resultados. La muestra fue considerada VPH positiva, cuando se observó una banda del tamaño esperado, en la amplificación de AR o BR, comparado con los controles positivos y no se observaron bandas en los controles negativos. Se consideró una infección mixta, cuando obtuvimos una banda en la reacción, tanto de AR como en la de BR (Figura 1).

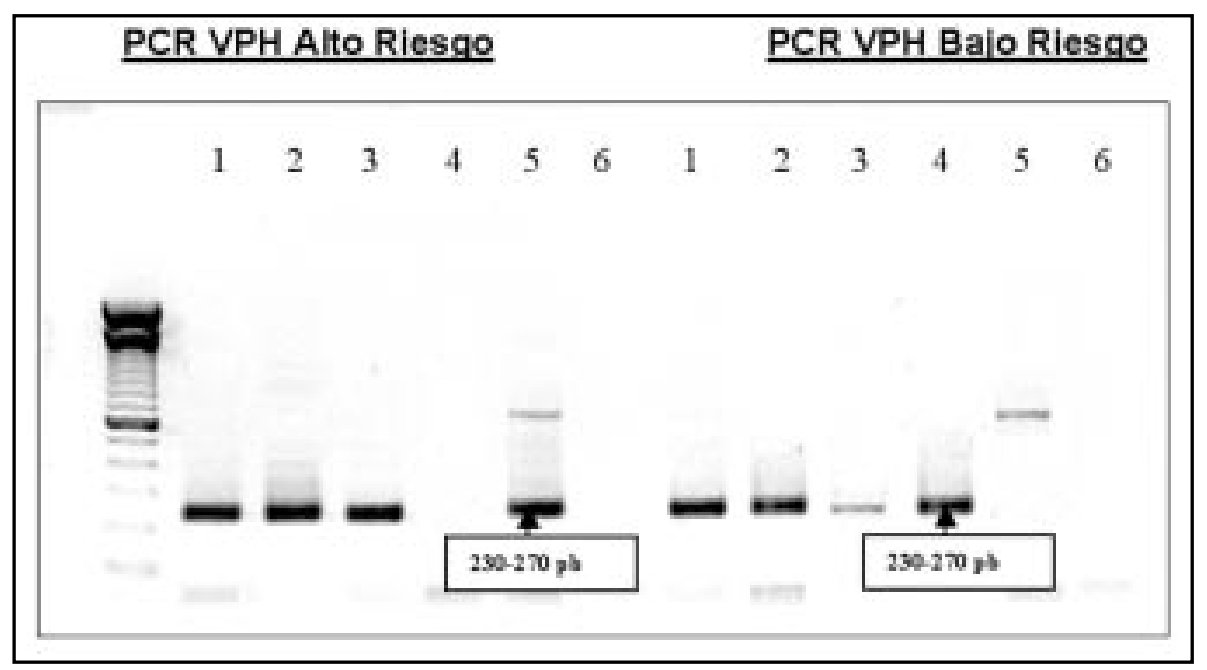

Figura 1. Detección VPH. PCR alto riesgo: 1-3. Muestras citobrush. 4. Control BR (VPH 11). 5. Control AR (VPH 16). 6. Blanco. PCR bajo riesgo: 1-3. Muestras citobrush. 4. Control BR (VPH 11). 5. Control AR (VPH 16). 6. Blanco. 
Estadística. Para el análisis estadístico de los resultados entre los distintos tipos de muestras y la detección de VPH, se utilizó la prueba exacta de McNemar.

\section{Resultados}

Características generales del grupo. La edad de las pacientes fluctuó entre 17 y 66 años, con un promedio de 38,7. Los diagnósticos histológicos incluyeron: 9 pacientes con lesiones de bajo grado (LBG) y 35 con lesiones de alto grado (LAG) (Tabla 1).

Amplificación el gen de B-globina. El 100\% de las muestras fueron B-globina positivas con 35 ciclos de amplificación, no existió necesidad de usar una PCR en nido. Las muestras de material fijado en formalina e incluido en parafina, mostraron degradación parcial del $\mathrm{ADN}$ con fragmentos mayoritariamente inferiores a $400 \mathrm{pb}$, en comparación con las obtenidas de tejido congelado y citobrush que presentaba predominantemente ADN de alto peso molecular.

Detección viral. El 100\% de las muestras obtenidas por CB fueron positivas para VPH, en cambio $84,1 \%$ y sólo $43,2 \%$ en las muestras de TF y TC fueron positivas, respectivamente. Se observaron diferencias estadísticamente significativas para la detección de VPH según el tipo de muestra: $\mathrm{CB} / \mathrm{TF}$ $\mathrm{p}=0,007, \mathrm{CB} / \mathrm{TC} \mathrm{p}<0,0001$ y $\mathrm{TF} / \mathrm{TC} \mathrm{p}=0,0002$ (Tabla 2). En las muestras de CB se detectó infección mixta (AR+BR) en 65,9\% y la positividad para VPH AR fue de 97,7\% (43/44) (Tabla 3). En relación al diagnóstico histológico, en las muestras de CB se encontró infección mixta en 77,7\% (7/9) de las LBG y en $62,8 \%$ (22/35) de las LAG (Tabla 3).
Tabla 1 C aracterísticas generales de las pacientes en estudio

\begin{tabular}{|llr|}
\hline Clasificación & $\begin{array}{l}\text { Diagnóstico } \\
\text { histológico }\end{array}$ & $\mathrm{n}$ \\
\hline Lesión bajo grado & VPH & 6 \\
& Displasia leve & 3 \\
Lesión alto grado & Displasia moderada & 16 \\
& Displasia intensa & 13 \\
& Carcinoma in situ & 6 \\
& Total & 44 \\
\hline
\end{tabular}

Tabla 2. Comparación entre las distintas muestras según la detección de VPH

\begin{tabular}{|lccc|}
\hline & \multicolumn{3}{c|}{ Detección VPH } \\
Muestras & Positivo & Negativo & $\%$ \\
\hline Citobrush & 44 & 0 & $100^{\mathrm{a}}$ \\
Tejido fijado & 36 & 8 & $81,8^{\mathrm{b}}$ \\
Tejido congelado & 19 & 25 & $43,2^{\mathrm{c}}$ \\
\hline
\end{tabular}

$\mathrm{p}_{\mathrm{ab}}=0,007, \mathrm{p}_{\mathrm{ac}}<0,0001, \mathrm{p}_{\mathrm{bc}}=0,0002$ prueba exacta de McNemar.

\section{ConCLusión}

La obtención de ADN de alta calidad es crítica para métodos genético-moleculares. Una de las fuentes más comunes usadas en patología molecular son los tejidos de archivo fijados en formalina e incluidos en parafina (TF), por ser el método de rutina utilizado en los laboratorios de patología y por su fácil almacenamiento. También es posible

Tabla 3. Positividad a H PV AR, H PV BR e infección mixta según tipo de muestra y diagnóstico histopatológico

\begin{tabular}{|lccccccccccccc|}
\hline & & \multicolumn{4}{c}{ Citobrush } & \multicolumn{4}{c}{ Tejido Fijado } & \multicolumn{4}{c|}{ Tejido Congelado } \\
Diagnóstico & $\mathrm{n}$ & AR & BR & Mixto & Neg & AR & BR & Mixto & Neg & AR & BR & Mixto & Neg \\
\hline LBG & 9 & 1 & 1 & 7 & 0 & 2 & 1 & 3 & 3 & 2 & 0 & 2 & 5 \\
LAG & 35 & 13 & 0 & 22 & 0 & 16 & 1 & 14 & 4 & 10 & 1 & 4 & 20 \\
TOTAL & 44 & 14 & 1 & 29 & 0 & 18 & 2 & 17 & 7 & 12 & 1 & 6 & 25 \\
$\%$ & 100 & 31,8 & $2,2 \%$ & $66 \%$ & 0 & $41 \%$ & $4,5 \%$ & $38,6 \%$ & 15,9 & $27,3 \%$ & $2,2 \%$ & $13,6 \%$ & 56,8 \\
\hline
\end{tabular}

AR: Alto riesgo. BR: Bajo riesgo. Mixto: Infección mixta (AR+BR). Neg: Caso negativo para AR y BR. LBG: Lesión de bajo grado. LAG: Lesión de alto grado. 
analizar mediante PCR, tejidos de más de 40 años de antigüedad ${ }^{19}$. Sin embargo, el ADN extraído desde el TF, muchas veces no es adecuado para amplificación por PCR, por el fraccionamiento o degradación que sufre el ADN durante el proceso de fijación ${ }^{20,24}$, tal como observamos en nuestros casos. Existen estudios que han probado diferentes métodos de fijación. La formalina-buffer al 10\% (pH neutro) está considerada como un fijador adecuado para preservar ADN en tejidos de archivo 20,25 . Como el TC no es sometido a procedimientos que puedan introducir inhibidores de la PCR o provocar degradación del ADN, es considerado una mejor fuente de ácidos nucleicos que el TF ${ }^{13,21}$.

De los 3 tipos de muestra estudiadas, la de CB resultó ser el mejor material para la detección de VPH con $100 \%$ de positividad en muestras con diagnóstico de lesión. Existen estudios que han comparado la eficacia de la citología de muestras de $\mathrm{CB}$ con muestras obtenidas mediante espátula o tórulas de algodón y claramente se ha demostrado que la calidad del frotis para diagnóstico con $\mathrm{CB}$ es superior ${ }^{26-28}$. Esto, porque el CB incorpora un barrido extenso tanto del endocervix como el exocervix, que permite recoger suficiente cantidad de células para el análisis. Además, una muestra de CB presenta las siguientes ventajas desde el punto de vista del laboratorio: se procesa en fresco y no es necesario congelarla ni someterla a fijación. El método de extracción del ADN es más rápido y con menos manipulación (lo que evita contaminación) que el aplicado al TC y al TF, donde la técnica es más laboriosa, aumentando el riesgo de contaminación ${ }^{21}$. Desde el punto de

\section{REFERENCIAS}

1. Bosch FX, Lorincz A, Muñoz N, Mejer CJ, Shah KV. The causal relation between human papillomavirus and cervical. J Clin Pathol 2002; 55: 244-65.

2. Muñoz N, Bosch FX, de SANjosé S, Herrero R, Castellsague $\mathrm{X}$, Shah KV et al. Epidemiologic classification of human papillomavirus types cervical cancer. N Engl J Med 2003; 348: 518-27.

3. MatSukURA T, SugASE M. Identification of genital human papillomaviruses in cervical specimens: segregation of specific virus types in specific clinicopathologic lesions. Int J Cancer 1995; 61: 13-22. vista clínico: puede ser fácilmente obtenida y a menor costo, debido a que se aprovecha el mismo cepillo una vez realizado el frotis para el Papanicolaou.

En nuestros resultados, el TF mostró mayor sensibilidad en la detección de VPH que el TC ( $81,8 \%$ vs $43,2 \%$ ). Esto podría deberse a que la muestra procesada de TC fue pequeña y obtenida de un área marginal del exocervix, no necesariamente de la zona con lesión. Por ello, la muestra de TC se obtuvo de áreas que potencialmente no alteraran el diagnóstico histológico. Diferente fue la situación del $\mathrm{TF}$, en el cual, solamente se microdisecó zonas con lesión.

En nuestra serie la infección mixta $A R / B R$ alcanzó a 65,9\% en las muestras de CB. Al separar los casos en LBG y LAG, fue de 77,7\% y 62,8\%, respectivamente. Jacob y cols, detectaron infección mixta en muestras de tejido cervical uterino en $25 \%(75 / 304)$ del total de sus casos ${ }^{29}$.

Concluimos que la detección/tipificación de VPH en muestras obtenidas mediante $\mathrm{CB}$, fue la mejor, pues se obtuvo una comelación de 100\% con el diagnóstico morfológico de VPH o lesión intraepitelial. A la luz de nuestros resultados, recomendamos la utilización del cepillado cervical para la obtención de muestras que permitan la identificación y tipificación de HPV en nuestra población. En este sentido la incorporación de la citología de fase líquida compatibiliza una mejor y más adecuada muestra para el estudio citológico de tamizaje y, para el eventual estudio del VPH mediante técnicas de biología molecular, especialmente en aquellas lesiones de carácter atípico y de significado incierto.

4. BuRD EM. Human papillomavirus and cervical cancer. Clin Microbiol Rev 2003; 16: 1-17.

5. Callaghan J, Karim S, Mortlock S, Wintert M, WOODWARD N. Hybrid capture as a means of detecting human papillomavirus DNA liquidbased cytology specimens: a preliminary evaluation. Br J Biomed Sci 2001; 58: 184-9.

6. Zehbe I, Wilander E. Two consensus primer systems and nested polymerase chain human papillomavirus detection in cervical biopsies: A study of sensitivity. Hum Pathol 1996; 27: 812-5.

7. Jacobs MV, de Roda Husman AM, van den Brule AJ, Snijders PJ, MejJer CJ, Walboomers JM. Group- 
specific differentiation between high and low risk human papillomavirus genotypes by general primer-mediated PCR and two of oligonucleotide probes. J Clin Microbiol 1995; 33: 901-5.

8. Nelson JH, Hawkins GA, Edlund K, Evander M, KJeldBerg L, WADELl G et al. A novel and rapid PCR-based method for genotyping human in clinical samples. J Clin Microbiol 2000; 38: 688-95.

9. Fujinaga $Y$, Shimada M, Okazana K, Fukushima M, Kato I, Fujinaga K. Simultaneous detection and typing of genital human using the polymerase chain reaction. J Gen Virol 1991; 72: 1039-44.

10. Qu W, Jiang G, Cruz Y, Chang CJ, Ho GY, Kiein RS ET AL. PCR detection of human papillomavirus: comparison between GP5+/GP6+ primer systems. J Clin Microbiol 1997; 35: 1304-10.

11. Pirog EC, Kieter B, Olgac S, Bobkiewicz P, Lundeman J, Quint WG ET AL. Prevalence of human papillomavirus DNA in different histological of cervical adenocarcinoma. Am J Pathol 2000; 157: 1055-62.

12. Husnak K, Grce M, Magdic L, Pavelic K. Comparison of five different polymerase chain reaction methods detection of human papillomavirus in cervical cell specimens. J Virol Methods 2000; 88: 125-34.

13. Zambrano A, Kalantari M, Simoneau A, Jensen JL, VILARREAL LP. Detection of human polyomavinuses and papillomavinuses in reveals the prostate as a habitat for multiple viral infections. Prostate 2002; 53: 263-76.

14. García F, Barker B, Santos C, Brown EM, Nuno T, Giulano A ET AL. Cross-sectional study of patient and physician collected cytology and human papillomavirus. Obstet Gynecol 2003; 102: 266-72.

15. Noda T, Sasagana T, Dong $Y$, Fuse H, Namiki $M$, INoue M. Detection of human papillomavirus (HPV) DNA in archival benign prostatic hyperplasia and prostatic cancer using a highly nested PCR method. Urol Res 1998; 26: 165-9.

16. Lorenzato FR, Singer A, Ho L, Santos LC, Batista R DE L, Lubambo TM et aL. Human papillomavirus detection for cervical cancer prevention polymerase chain reaction in self-collected samples. Am J Obstet Gynecol 2002; 186: 962-8.

17. HJerpe A, Lindh E, Bistoletti P, George J, Groff D. Use of cervical cytobrush samples for dot-blot detection and typing of human papillomaviruses using subgenomic probes. Anal Quant Cytol Histol 1990; 12: 299-305.

18. Jacobs MV, Zieunski D, Mejer CJ, Pol RP, VoorHORST FJ, DE SCHIPPER FA ET AL. A simplified and reliable HPV testing of archival Papanicolaou cervical smears: application to cervical smears from cancer starting with cytologically normal smears. Br J Cancer 2000; 82: 1421-6.

19. Shibata D, Martin WJ, Arnheim N. Analysis of DNA sequences in forty years old paraffin-embedded sections: a bridge between molecular biology and classical. Cancer Res 1988; 48: 4564-6.

20. Greer CE, Peterson SL, Kiviat NB, Manos MM. PCR amplification from paraffin-embedded tissues. Effects of fixation time. Am J Clin Pathol 1991; 95: $117-24$.

21. WRIGHT DK MM. Sample preparation from paraffin-embedded tissues. In: Innis M GD, Sninsky J, White T, editor. PCR protocols. A guide to Methods and Applications. San Diego, CA: Editorial Academic Press, Inc; 1990; p 153-8.

22. Melo A, Montenegro S, Hooper T, Capurro I, Roa J, RoA I. Tipificacion del virus papiloma humano (VPH) en lesiones preneoplásicas y carcinoma del cuello uterino en mujeres de la IX regiónChile. Rev Méd Chile 2003; 131: 1382-90.

23. Saiki RK, Scharf S, Faloona F, Muшs KB, Horn GT, ERLCH HA ET AL. Enzymatic amplification of beta-globin genomic sequences and site analysis for diagnosis of sickle cell anemia. Science 1985; 230: 1350-4.

24. Rammou-Kinia R, Anagnostopoulou I, Gomousa M. Comparison of spatula and nonspatula methods for cervical. Acta Cytol 1991; 35: 69-75.

25. Peng HQ, Roth P, Caussy D, Rawls W. Comparison of the cytobrush and cotton swabs in sampling for filter in situ hybridization detection of human 16 and 18 DNA. Acta Cytol 1988; 32: 311-3.

26. Redondo Horcajo AM, Guerra Merino A, Pinedo Garrido G, García Aranda R. Prevention of cervix cancer. Comparison of the sample quality obtained using cotton swab or cervical brush. Aten Primaria 2000; 26: 38-41.

27. Jacobs MV, Snijders PJ, van den Brule AJ, Helmerhorst TJ, MejJer CJ, Walboomers JM. A general primer GP5+/GP6(+)-mediated PCR-enzyme immunoassay rapid detection of 14 high-risk and 6 low-risk human genotypes in cervical scrapings. J Clin Microbiol 1997; 35: 791-5.

28. SHIBATA D. Extraction of DNA from paraffin-embedded tissue for analysis by chain reaction: new tricks from an old friend. Hum Pathol 1994; 25: 561-3.

29. THOMPSON CH, Rose BR Deleterious effects of formalin/acetic acid/alcohol (FAA) detection of HPV DNA by in situ hybridization and the polymerase reaction. Pathology 1991; 23: 327-30. 